abortion was prevented by progesterone substitution in women luteectomized early in the first trimester. Therefore it seems that the degree of progesterone deficiency found in the patients in the present study could have upset the regulatory balance enough to provoke precocious uterine activity and premature labour.

In this context the case of another patient, excluded from the study because the criteria for entry were not satisfied, is of interest. She was admitted at 30 weeks' gestation with no symptoms of threatened premature labour but because of cervical dilatation and effacement due to incompetence of the cervix. Despite this, subsequent rupture of the membranes, and a small fetus $(1,900 \mathrm{~g})$ premature labour did not begin until induced by oxytocin. The oestradiol level at 30 weeks was normal $(12 \mathrm{ng} / \mathrm{ml})$ but the progesterone level (200 $\mathrm{ng} /$ $\mathrm{ml}$ ) exceeded the normal control value $(159 \mathrm{ng} / \mathrm{ml})$. The placenta $(500 \mathrm{~g})$ also exceeded the normal weight (425 g). Apparently in this patient pregnancy was maintained by a decreased oestradiol/progesterone ratio.

Though the causes of the progesterone deficiency and the increased oestradiol/progesterone ratio in the study group of patients remains unexplained, the recognition that this regulatory imbalance characterizes some types of threatened pregnancies is a step towards understanding the aetiology of premature labour and thus its prevention. Since there are inherent difficulties in correcting progesterone deficiency therapeutically when the placenta is the site of progesteronegenesis, stimulation of placental growth and function seems an appropriate measure. This possibility is now being explored (Csapo, 1971). Another rational course would be to restore the prostaglandin/progesterone balance by suppressing prostaglandin synthesis. Some success in this direction has already been achieved (Csapo et al., 1973 b).
This study was supported by the Agency for International Developmen+, Department of State, contract No. AID/csd 3160; by the Population Council, subcontract 006, AID/csd 2491; by the National Institutes of Health, contract No. 69-2194; and by the National Institutes of Health Career Award HD 20169-10.

\section{References}

Caldwell, B. V., Tillson, S. A., Brock, W. A., and Speroff, L. (1972) Prostaglandins, 1, 217

Csapo, A. I. (1969). In Ciba Foundation Study Group No. 34, Progesterone: Its Regulatory Effect on the Myometrium, ed. G. E.W. Wolstenholme and J. Knight. Londor, Churchill.

Csapo, A. I. (1971). In Contractile Proteins and Muscle, ed. K. Laki, p. 413 New York, Dekker.

Csapo, A. I. (1972). Fournal of Reproductive Medicine, 9, 400

Csapo, A. I., Jaffin, H., Kerenyi, T., De Mattos, C. E. R., and Sousa-Filho, M. B. (1963). American fournal of Obstetrics and Gynecology, 87, 892 Csapo, A. I., Sauvage, J. P., and Wiest, W. G. (1970). American fournal of Obstetrics and Gynecology, 108, 950

Csapo, A. I., Knobil, E., Van Der Molen, H. J., and Wiest, W. G. (1971). American fournal of Obstetrics and Gynecology, 110, 630.

Csapo, A. I., Kivikoski, A., and Wiest, W. G. (1972 a). Prostaglandins, 2, 125.

Csapo, A. I. Pulkkinen, M. O., Ruttner, B., Sauvage, J. P., and Wiest, W. G. (1972 b). American fournal of Obstetrics and Gynecology, 112, 1061 .

Csapo, A. I., Pulkkinen, M. O., and Wiest, W. G. (1973 a). American Fournal of Obstetrics and Gynecology, 115, 759 .

Csapo, A. I., Csapo, E. F., Fay, E., Henzl, M., and Salau, G. (1973 b) Prostaglandins. In press.

Eastman, N. J., and Hellman, L. M. (editors) (1966). In Williams Obstetrics, 13 th edn. New York, Meredith.

Kaihola, H. L., Wiest, W. G., and Csapo, A. I. (1973). Unpublished observations.

Perry, J. S. (1972). Journal of Reproduction and Fertility, Suppl. No. 16.

Poyser, N. L., Horton, E. W., Thompson, C. J., and Los, M. (1971). Nature, 230, 526.

Pulkkinen, M. O., Liukko, P., Piiroinen, O., and Rauramo, L. (1973). Acto Obstetricia et Gynecologica Scandinavica, 52, 9.

Rado, A., Crystle, C. D., and Townsley, J. D. (1970). Journal of Clinical Endocrinology, 30, 497.

\title{
The Mallory-Weiss Syndrome
}

\author{
D. J. B. ST. JOHN, J. P. MASTERTON, N. D. YEOMANS, H. A. F. DUDLEY
}

British Medical fournal, 1974, 1, 140-143

\section{Summary}

A policy of immediate investigation of patients with haematemesis or melaena or both led to the diagnosis of the Mallory-Weiss syndrome in 16 out of 121 patients admitted to a combined medical-surgical unit over three and a half years. A typical history suggestive of the diagnosis was obtainable in only nine of the 16 patients, though recent alcohol intake was high in another four. All patients survived the episode. Establishment of the diagnosis by oesophagogastroscopy was of special benefit when surgery was needed for control of continuing blood loss, but it also simplified the subsequent medical man-

Monash University Medical School, Alfred Hospital, Melbourne 3181, Australia

D. J. B. ST. JOHN, F.R.A.C.P., M.R.C.P., Senior Lecturer, Department of

P. MASTERTON, F.R.C.s., F.R.A.C.s., Associate Professor, Department of N. D. YEOMANS, M.R.A.C.P., Research Fellow, Department of Medicine (Present address: Anatomy Department C, University of Copenhagen, Copenhagen)

H. A. F. DUDLEY, CH.M., F.R.C.S., Chairman and Professor, Department of Surgery (Present address : Surgical Unit, St. Mary's Hospital, London of Surgery agement of those patients in whom bleeding stopped spontaneously. The incidence of $13.2 \%$ in this series suggests that the Mallory-Weiss syndrome may be a relatively common cause of upper gastrointestinal bleeding.

\section{Introduction}

For the three decades after its original description (Mallory and Weiss, 1929) the Mallory-Weiss syndrome was thought to be a rare cause of upper gastrointestinal bleeding. More recently, however, reports of cases have raised the possibility that the syndrome might not be so uncommon (Atkinson et al., 1961; Dobbins, 1963; Freeark et al., 1964; Dagradi et al., 1966; Homes, 1966), and in series where early endoscopy has been used routinely in the investigation of haematemesis and melaena the incidence has been found to be $2.0 \%$ (Katz et al., 1965), $2.7 \%$ (Jones, 1969), 5.1\% (Palmer, 1970), and $4.7 \%$ (Pitcher, 1972). An incidence of $14.7 \%$ was reported in the United States army and veteran patients (Wells, 1967), but there was an unduly high proportion of alcoholics in this group. In these series endoscopy was performed either exclusively or, for the most part, with rigid and semi-rigid instruments. The recent introduction of fibreoptic instruments has greatly improved the ease and accuracy of endoscopic examination of the upper gastrointestinal tract. In our medical and surgical unit a policy of 
immediate investigation of all cases of major upper gastrointestinal bleeding was introduced early in 1970. Endoscopy with a forward-viewing fibreoptic endoscope was performed as the initial investigation on most patients, usually within eight hours of the time of admission to hospital. We report the finding of an unexpectedly high incidence of the Mallory-Weiss syndrome.

\section{Patients and Methods}

The cases of Mallory-Weiss syndrome were diagnosed from among patients with major upper gastrointestinal bleeding admitted to the Monash University Departments of Medicine and Surgery at this hospital in the three-and-a-half-year period beginning on 1 February 1970. Customarily patients with haematemesis or melaena are admitted to the medical units of the hospital and therefore our patients were mostly admitted to the department of medicine, where the preliminary investigation was undertaken. The department of medicine is only one of seven general medical units in a 480 -bed hospital. Consequently the total number of patients with bleeding in this series is relatively small. Altogether there were 121 patients with haematemesis or melaena in the three and a half years of review: 89 had haematemesis with or without melaena, 32 had melaena alone. There were 91 men and 30 women and the mean age ( \pm S.D.) was $55.4 \pm 16.5$ years (range $17-97$ years).

Before February 1970 most patients in our unit with haematemesis or melaena underwent early investigation by barium meal and by gastroscopy with a Hirschowitz fibre-gastroscope. After the acquisition of two sophisticated fibre-endoscopes (Olympus EF oesophagoscope and Olympus GFB gastroscope) a more active policy of investigation was begun. On admission all patients were assessed jointly by a physician and a surgeon. Provided that immediate surgery was not indicated, and that was a rare necessity, a plan of investigation was formulated according to the clinical indications present in each case. Endoscopy and barium-meal examination were both available on a 24-hour emergency service basis. Either endoscopy or bariummeal examination was performed as soon as immediate resuscitation permitted. This was then followed by the alternative investigation if the first method failed to show a lesion thought to be the cause of the bleeding. The aim was to establish the site of bleeding as soon as possible, preferably within six or eight hours of admission. Because of the difficulty in performing endoscopy soon after barium-meal examination this was performed first, unless the clinical features strongly suggested the diagnosis of a chronic ulcer. In the latter instance, however, barium-meal examination was performed before endoscopy only if there were no additional clinical features, such as recent salicylate ingestion, to suggest the possibility of more than one lesion being present. As a result endoscopy was performed on 90 of the 121 patients within 24 hours of admission and usually within six to eight hours.

Several modifications of the routine of investigation were introduced in the course of the first 18 months. Thus, to avoid the problem of interpretation of lesions which might be due to artefact, it was decided to forgo any attempt at gastric aspiration before endoscopy so that the latter could be performed without prior intubation of the oesophagus and stomach: this approach has recently been advocated by Morrissey (1972). The forwardviewing Olympus EF was then routinely used before the Olympus GFB because of the lack of a satisfactory aspiration channel on the fibre-gastroscope. Late in 1970 a flow sheet was introduced to promote consistent decision making in the selection of the initial investigative technique (Dudley et al., 1973). In November 1971 endoscopic facilities were extended by the purchase of an Olympus GIF panendoscope.

\section{Results}

The diagnosis of Mallory-Weiss syndrome was established in 16 patients in the three and a half years of the study. The criterion for the diagnosis was the finding of single or multiple longitudinal mucosal tears at, or immediately below, the gastrooesophageal junction, irrespective of the presence or absence of a history of vomiting before haematemesis.

Data on the group are given in table I. The mean age ( \pm S.D.) was $45 \pm 13$ years. The sex distribution was identical with that of the total 121 patients with upper gastrointestinal bleeding. A factor responsible for development of a mucosal tear was identifiable in 10 cases-vomiting or dry-retching preceded haematemesis in nine and paroxysmal coughing due to acute bronchitis appeared to be responsible in one. A further four patients had had a high consumption of alcohol before the episode of bleeding but they were unable to recall vomiting before the haematemesis.

No precipitating factor could be identified in the two remaining cases. In one patient haematemesis occurred with the initial bout of vomiting, and endoscopy (Olympus GIF) showed bleeding from a gastro-oesophageal tear, and a chronic duodenal ulcer which was not bleeding. The other patient had neither vomiting nor haematemesis but he collapsed after the onset of melaena. Oesophagoscopy was not performed because of the lack of any clinical features suggesting an oesophageal cause and gastroscopy and barium-meal examination failed to identify a definite lesion. When laparotomy was undertaken because of continuing blood loss bleeding was found to be coming from a linear mucosal tear immediately below the gastro-oesophageal junction.

TABLE 1-Details of Cases of Mallory-Weiss Syndrome

\begin{tabular}{|c|c|c|c|c|c|c|c|}
\hline $\begin{array}{l}\text { Case } \\
\text { No. }\end{array}$ & $\begin{array}{c}\text { Age } \\
\text { (years) }\end{array}$ & Sex & $\begin{array}{l}\text { Factor Precipitating } \\
\text { Mucosal Tear }\end{array}$ & $\begin{array}{l}\text { Basic Cause of } \\
\text { Mucosal Tear }\end{array}$ & Endoscopic Findings* & $\begin{array}{l}\text { Radiological Findings } \\
\text { (Barium Meal) }\end{array}$ & Operative Findings \\
\hline $\begin{array}{l}1 \\
2 \\
3 \\
4\end{array}$ & $\begin{array}{l}21 \\
50 \\
54 \\
40\end{array}$ & $\begin{array}{l}\text { M. } \\
\text { M. } \\
\text { F. }\end{array}$ & $\begin{array}{l}\text { Vomiting } \\
\text { Undetermined } \\
\text { Undetermined } \\
\text { Vomiting }\end{array}$ & $\begin{array}{l}\text { Alcohol } \\
\text { Alcohol } \\
\text { Alcohol } \\
\text { Alcohol }\end{array}$ & $\begin{array}{l}1 \text { Tear } \\
\text { 1 Tear } \\
\text { Bleeding from gastro- }\end{array}$ & $\begin{array}{l}\text { Normal } \\
\text { Normal } \\
\text { Normal }\end{array}$ & $\begin{array}{l}\overline{3} \text { Tears } \\
1 \text { Tear }\end{array}$ \\
\hline $\begin{array}{l}5 \\
6 \\
7\end{array}$ & $\begin{array}{l}43 \\
60 \\
60\end{array}$ & $\begin{array}{l}\text { M. } \\
\text { M. }\end{array}$ & $\begin{array}{l}\text { Vomiting } \\
\text { Vomiting } \\
\text { Undetermined }\end{array}$ & $\begin{array}{l}\text { Alcohol } \\
\text { Alcohol } \\
\text { Unknown }\end{array}$ & $\begin{array}{l}3 \text { Tears } \\
1 \text { Tear } \\
\text { Oesophagoscopy not } \\
\text { performed. Gastro- } \\
\text { scopy normal }\end{array}$ & $\begin{array}{l}\text { Normal } \\
\text { Normal } \\
\text { Deformed duodenal cap }\end{array}$ & $\begin{array}{l}\overline{1} \text { Tear Duodenotomy: } \\
\text { normal duodenal } \\
\text { mucosa }\end{array}$ \\
\hline 8 & 50 & M. & Vomiting & Alcohol & $\begin{array}{l}1 \text { Tear with active } \\
\text { bleeding }\end{array}$ & - & 2 Tears \\
\hline 9 & 69 & M. & Undetermined & Uncertain & 2 Tears and a chronic & Chronic duodenal ulcer & \\
\hline $\begin{array}{l}10 \\
11 \\
12 \\
13\end{array}$ & $\begin{array}{l}43 \\
28 \\
54 \\
44\end{array}$ & $\begin{array}{l}\text { F. } \\
\text { M. } \\
\text { M. }\end{array}$ & $\begin{array}{l}\text { Vomiting } \\
\text { Coughing } \\
\text { Undetermined } \\
\text { Undetermined }\end{array}$ & $\begin{array}{l}\text { Gastroenteritis } \\
\text { Acute bronchitis } \\
\text { Alcohol } \\
\text { Alcohol }\end{array}$ & $\begin{array}{l}2 \text { Tears } \\
1 \text { Tear } \\
1 \text { Tear } \\
\text { (a) Bleeding from } \\
\text { gastro-oesophageal }\end{array}$ & $\begin{array}{l}\text { Small hiatus hernia } \\
\text { Normal } \\
\text { Normal } \\
\text { Normal }\end{array}$ & $\bar{z}$ \\
\hline $\begin{array}{l}14 \\
15 \\
16\end{array}$ & $\begin{array}{l}31 \\
37 \\
42\end{array}$ & $\begin{array}{l}\text { M. } \\
\text { F. }\end{array}$ & $\begin{array}{l}\text { Dry-retching } \\
\text { Vomiting } \\
\text { Vomiting }\end{array}$ & $\begin{array}{l}\text { Alcohol } \\
\text { Alcohol } \\
\text { Alcohol }\end{array}$ & $\begin{array}{l}1 \text { Tear } \\
2 \text { Tears } \\
1 \text { Tear }\end{array}$ & $\begin{array}{l}\text { Normal } \\
\text { Normal } \\
\text { Normal }\end{array}$ & $=$ \\
\hline
\end{tabular}

* Tear = Gastro-oesophageal tear. 
In 12 of the 16 patients a linear mucosal tear typical of the Mallory-Weiss lesion was identified at oesophagogastroscopy performed as the first investigation in hospital with a forwardviewing endoscope. The diagnosis was suspected in two more patients when active bleeding was observed at the gastrooesophageal junction, and the diagnosis was confirmed by repeat oesophagoscopy 24 hours later in one and at laparotomy in the second. Diagnosis of the remaining two was made at laparotomy. Rapid bleeding precluded investigation of one of these and the other who had melaena but not haematemesis has been described already. At endoscopy particular care was taken to advance the instrument slowly to obtain views ahead of the distal end of the instrument and in that way to avoid diagnostic problems created by contact with the mucosa. Whenever a mucosal tear was seen gastroscopy was performed to exclude an additional abnormality such as gastric erosions. However, duodenoscopy was usually not attempted because of the possibility of distortion of the cardia during passage of the instrument through the pylorus, with the risk of exacerbation of bleeding from the tear.

The severity of blood loss varied greatly. Blood transfusion was not needed in four of the 16 patients but, in contrast, continued bleeding and failure of resuscitative measures necessitated laparotomy in four others. In the latter cases the mucosal tears were obliterated by interrupted silk sutures. All 16 patients survived without complication.

The final diagnoses established in the 121 patients in the series are listed in table II. The incidence of the MalloryWeiss syndrome was $13.2 \%$. While the commonest cause of haemorrhage was chronic duodenal ulcer $(36.4 \%)$, the second commonest was the Mallory-Weiss syndrome and chronic gastric ulcer equally.

TABLE II-Final Diagnosis in 121 Patients with Haematemesis or Melaena or Both Disorders

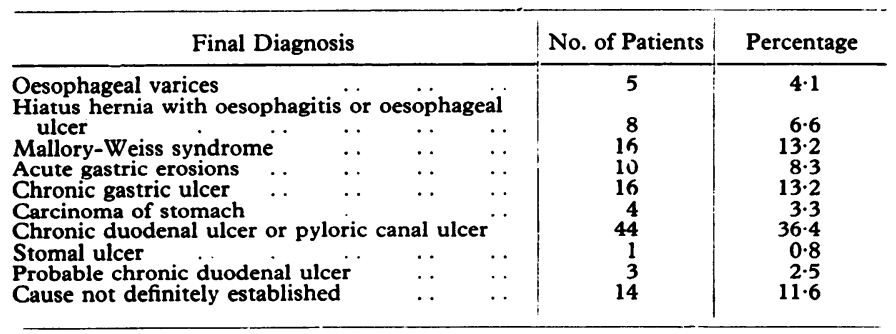

Among the patients in whom no diagnosis was established, one had features of the Mallory-Weiss syndrome but because of his inability to co-operate with even the simplest of medical procedures oesophagoscopy was contraindicated and the clinical diagnosis could not be proved.

Though oesophagoscopy was always available investigations were restricted at times by delays with servicing of the gastroscope and the duodenoscope. A complete range of investigations was not performed on many of the patients in whom no diagnosis was made and the results cannot therefore be expected to show the full diagnostic capabilities of endoscopic examination.

\section{Discussion}

Though the diagnosis of Mallory-Weiss syndrome has been restricted in the past to cases in which vomiting has preceded haematemesis, the criteria for diagnosis of the syndrome have been widened to include cases where haematemesis has been caused by spontaneous mucosal tearing at the gastro-oesophageal junction, regardless of the precipitating factor (Atkinson et al., 1961; Weaver et al., 1969). In this series precipitating factors were identified in 10 instances and four other patients had had a high recent alcohol intake. As several of these four patients were unable to recall clearly the events leading up to haematemesis, vomiting or dry-retching may indeed have occurred before haematemesis even though the information was unobtainable. Some doubts must persist in the single case where there was neither vomiting nor haematemesis because of the apparent absence of any cause of mucosal laceration. It is possible that the lesion was a single acute gastric ulcer but its site and linear nature were characteristic of a Mallory-Weiss tear. Classification of acute haemorrhagic lesions at the gastro-oesophageal junction can be difficult when they are not linear (Delumeau et al., 1972) and in our series one such case which was encountered was not included in the Mallory-Weiss group.

The factors which determine the incidence of Mallory-Weiss syndrome as a cause of upper gastrointestinal bleeding include the technique and timing of investigations, the method of selection of patients for endoscopy, and the population from which the patients are drawn. In two large series in which semirigid and rigid instruments were used the incidence of MalloryWeiss syndrome was $2.7 \%$ (Jones, 1969) and 5.1\% (Palmer, 1970). Introduction of forward-viewing fibreoptic instruments for upper gastrointestinal endoscopy has greatly facilitated the ease and accuracy of examination of the gastro-oesophageal junction, and the incidence of the syndrome therefore needs to be reassessed (Cremer et al., 1973). The new instruments provide circumferential views of the lumen and the manœuvrability of the distal end allows careful examination of the mucosa. With the older instruments gastroscopy was more successful than oesophagoscopy for the identification of mucosal tears (Dagradi et al., 1966; Jones, 1969; Palmer, 1970). In our experience with fibre-endoscopes the forward-viewing instruments are far superior to the side-viewing Olympus GFB gastroscope for examination of the gastro-oesophageal junction. Timing of investigations is of paramount importance as rapidly-healing acute mucosal lesions may not be diagnosed if endoscopy is delayed for 48 or even 24 hours.

Though the incidence of $13.2 \%$ for the Mallory-Weiss syndrome is much higher than in most other series particular care was taken to avoid any manœuvres which might cause artefactual mucosal lesions. The special features of our series are that the population studied comprised all patients with clear evidence of major gastrointestinal bleeding admitted to a medical and surgical unit in a general teaching hospital, and that a policy of immediate investigation was followed, with oesophagogastroscopy as the first investigation in most patients. Over the three and a half years there has been no apparent change in the pattern of admissions to the combined unit. While many of the patients with Mallory-Weiss syndrome had a heavy and regular consumption of alcohol, this hospital has no special reputation for the treatment of alcoholism and we think that the socioeconomic status of the patients studied would be similar to that in most Australian teaching hospitals. The lack of any bias towards admission of alcoholic patients is supported by the incidence of only $4.1 \%$ for bleeding oesophageal varices.

Apart from providing greater precision in diagnosis, the value of early endoscopy has been challenged, mainly because of the failure to show that early diagnosis affects the prognosis favourably. However, an important practical value of early endoscopy is in the detection of oesophageal and juxtaoesophageal sites of bleeding (Cotton et al., 1973). One advantage of performing endoscopy within several hours of admission to hospital is that nasogastric intubation can be delayed with safety until after the endoscopy to avoid producing artefact, but it can then be used in selected cases for detection of continuing or recurrent haemorrhage. Even if the presence of blood interferes with examination of the stomach and duodenum at this early stage the advantages of oesophagoscopy alone would seem to justify the approach. In our series there was an oesophageal or juxtaoesophageal site of bleeding in $24 \%$ of the cases (table II). There were no particular features to indicat: the diagnosis of the Mallory-Weiss syndrome in seven of the 16 cases and the diagnosis was made only because early oesophagoscopy was used. When surgical intervention is 
needed because of continued bleeding correct preoperative diagnosis of the syndrome could greatly reduce the length of the surgical procedure for a condition which can be difficult to identify at laparotomy. When bleeding stops spontaneously the emphasis of medical advice can be correctly placed on reduction of alcohol consumption (where appropriate) rather than on the unnecessary prescription of antacids or anticholingergics. Finally, a selective policy of treatment with vasopressin (Dill et al., 1972) requires accurate identification of the bleeding point.

\section{References}

Atkinson, M., et al. (1961). Gut, 2, 1.
Cotton, P. B., Rosenberg, M. T., Waldram, R. P. L., and Axon, A. T. R. (1973). British Medical fournal, 2, 505.

Cremer, M., Gulbis, A., Peeters, J. P., and Desneux, J. J. (1973). In Urgent Endoscopy of Digestive and Abdominal Diseases, ed. Z. Maratka, p. 132. Basel, Karger.
Dagradi, A. E., Broderick, J. T., Juler, G., Wolinsky, S., and Stempien, S. J. (1966). American fournal of Digestive Diseases, 11, 710.

Delumeau, G., Perrin, D., de Lisle, L. R., Veyrac, Y., and Miniconi, P. (1972). Annales de Gastroénterologie et d'Hépatologie, 8, 329.

Dill, J. E., Wells, R. F., and Levy, M. (1972). Gastrointestinal Endoscopy, $18,157$.

Dobbins, W. O. (1963). Gastroenterology, 44, 689.

Dudlev, H. A. F., St. John, D. J. B., and Masterton, J. P. (1973). Proceedings of the 46th General Scientific Meeting of the Royal Australasian College

Freeark, R. J, Norcross, W. J, Pak ., Norcross, . J., Baker, R. J., and Strohl, E. L. (1964) Archives of Surgery, 88, 882.

Holmes, K. D. (1966). Annals of Surgery, 164, 810.

Jones, F. A. (1969). British Medical fournal, 2, 267

Katz, D., Freud, M., and McKinnon, W. M. P. (1965). American fournal of Digestive Diseases, 10, 314.

Mallory, G. K., and Weiss, S. (1929). American fournal of Medical Sciences, 178, 506.

Morrissev, J. F. (1972). Gastroenterology, 62, 1241.

Palmer, E. D. (1970). In Upper Gastrointestinal Haemorrhage. Springfield Illinois, Thomas.

Pitcher, J. L. (1972). Gastrointestinal Endoscopy, 18, 122.

Weaver, D. H., Maxwell, J. G., and Castleton, K. B. (1969). American Fournal of Surgery, 118, 887.

Wells, R. F. (1967). Southern Medical Fournal, 60, 1197.

\section{Tuberculous Lymphadenitis}

\section{P. B. ILES, P. A. EMERSON}

British Medical fournal, 1974, 1, 143-145

\section{Summary}

A total of 43 episodes of tuberculosis lymphadenitis were treated in 32 adult patients. In 12 instances the affected lymph node was excised without any chemotherapy; there were 10 relapses. The treatment was local excision of the affected lymph nodes together with antituberculosis chemotherapy with at least two drugs in 30 instances; there were no relapses following such therapy.

Presumably patients with tuberculosis lymphadenitis are still sometimes treated with surgery alone because that was at one time the orthodox line of surgical teaching. Such a view is out of date: these patients should always be given antituberculosis therapy in addition to any surgical measures.

\section{Introduction}

While reviewing the results of treatment of adult patients with various forms of tuberculosis in Westminster Hospital during the period January 1965 to May 1973 we found that they were much less satisfactory in cases of tuberculous lymhadenitis than in those of other types of tuberculosis. This was a matter for concern and we decided to study these cases more closely. This paper reports our findings.

\section{Patients and Diagnosis}

Of the 32 patients with tuberculous lymphadenitis treated during the eight-year period 20 were females aged 15 to 76 years and 12 were males aged 15 to 50 years; 14 were from abroad. Altogether 25 patients were referred by general practitioners and five by other hospitals; two developed their tuberculous lymphadenopathy while they were already on

Westminster Hospital, London SW1P 2AP

P. B. ILES, M.B., M.R.C.P., Registrar in Medicine

P. A. EMERSON, M.D., F.R.C.P., Consultant Physician chemotherapy for pulmonary tuberculosis. The follow-up details of those no longer attending the hospital were obtained from the patients and their medical praotitioners.

Twenty-seven patients had no evidence of other organ involvement; in three there was also active pulmonary tuberculosis and in one there was tuberculous peritonitis; the other patient also had miliary tuberculosis with pulmonary and meningeal involvement.

In 30 patients the diagnosis of tuberculous lymphadenitis was confirmed by excision biopsy either before or after reference to Westminster Hospital. In the other two the diagnosis was made by examination of pus obtained by needle aspiration without biopsy. The biopsy specimens were examined for acid-fast bacilli by routine histological methods and by fluorescent microscopy. Characteristic histological changes of tuberculosis were reponted in every biopsy specimen.

In 10 of the 30 specimens acid-fast bacilli were seen microscopically in either the histological preparations or the bacteriological smears. In two instances only formalin specimens had been sent to the laboratory, so that culture was not possible, but 14 cultures positive for mycobacteria were obtained from the other 28 . Of the 14 myoobacteria which were cultured 13 proved to be human-strain organisms. The other organism was mycobacterium scrofulaceum, which was sensitive only to cycloserine and ethionamide. Ten of the humanstrain mycobacteria were fully sensitive to all antituberculosis drugs tested; one was resistant only to streptomycin, one only to isoniazid, and one only to para-aminosalicylic acid (PAS).

\section{Treatment and Results}

Though the 32 patients were finally treated at Westminster Hospital seven had had one or more previous episodes treated surgically elsewhere. This and the fact that the patients were treated by a number of different surgeons and physicians account for the variations in the treatment given.

Of the patients who received chemotherapy one was given only streptomycin but the others all had standard treatment with at least two drugs. PAS and isoniazid were used most frequently in the earlier years but later PAS was largely replaced by rifampicin. Ethambutol was the usual choice of 